\title{
MANAGERIAL ASSISTANCE: PROMISES AND PITFALLS $*$
}

\author{
Thomas P. Ference**
}

\section{Tife Dimensions of Managerial Assistance}

Minority owned and managed businesses are the keystone in any serious attempt to foster community economic development. While it is true that minority group members are likely to spend most of their working careers in the employ of others, just as do their white counterparts, the importance of minority enterprise as both a symbolic and a social force cannot be denied. ${ }^{1}$ One of the primary forces for integration and cohesion in a developing community is the existence of a flourishing business community. This sector provides not only the jobs and the sources of capital that the larger community needs for further development, but it also provides the leaders, the symbols of success, and the stability needed to insure continued motivation towards further development. While the primary function of this business sector may be the provision of services, particularly retail services, to its own community, it is also essential that it participate fully in the larger market place. This insures the complete interaction of the minority community with the larger economic system.

It is too often true in our cities at present that the economic subsystem represented by the minority community is asymmetrically related to the larger economic system. The flow of funds (working capital) out of the minority community greatly exceeds the flow of funds into it from the larger system, and the minority community consumes proportionately a greater share of the goods and services proffered by the larger system than the system consumes of the goods and services proffered by the minority community. This results in two phenomena, the first of which is widely recognized and easily demonstrated, the second of which is more subjective but in the long run more invidious. The first is the provision of funds to the minority community by means of various government programs such as welfare and unemployment insurance. While this maintains the level of consumption behavior

- I would like to thank George A. Fraser, Robert Lenzner, and Hoke S. Simpson for the guidance and insight derived from many conversations over the past four years, and Albert White for assistance in researching this paper.

t The preparation of this paper was made possible in part by a grant from the Faculty Research Fund of the Graduate School of Business of Columbia University.

** Assistant Professor of Business, Graduate School of Business, Columbia University.

${ }^{1}$ It is not claimed that small business development is a solution to all of the economic ills of minority communities. Those who might rely solely on such a solution overlook the realties of the economic system. As will be seen below, the focus of this piece is on those small businesses which provide symbolic evidence of the capabilities of minority businessmen and which can further the participation of the minority community in the larger economic system. 
in the minority community, it has no multiplier effects for the economic subsystem. Thus, while in static terms the system is stable and closed, in dynamic terms, there is no contribution to the economic growth potential of the minority area. This leads to the second phenomenon-the long-run decay of the economic subsystem of the minority area. Without either an influx of working capital to the minority community or retention of such capital as exists in the community, the long-run effects of the cycle described above result in an ever-widening gap between the two systems. This process highlights the need for a strong, indigenous business sector which acts as a manager of capital and provides the necessary linkage between the minority community and the larger capital markets.

The need for either injections of capital or more efficient use of existing capital in minority areas has long been recognized by proponents of community economic development. $^{2}$ It has become increasingly apparent, however, from the experiences of the various lending and capital financing programs the past decade, that the mere influx of capital is not sufficient to meet the needs of the minority communities. In fact, capital alone may do more harm than good. Capital provided for starting new businesses or bolstering existing businesses is usually accompanied by considerable publicity and the raising of great expectations that the long-term process of decay and disenfranchisement from the economic system is being reversed. Capital represents, however, only the promise of participation in a business and in the economic system; capital must be managed properly if it is to fulfill this promise. Thus, in recent years, the critical need for managerial assistance in minority economic development has been recognized. It is the purpose of this paper to examine the many aspects of managerial assistance as they interact with the long-run goals of community economic development.

\section{A. Distinguishing the Forms of Assistance}

Managerial assistance is an umbrella-like term covering many forms of interaction between majority businessmen and representatives of government agencies with minority entrepreneurs and members of community organizations. In its broadest sense, it is concerned with improving the performance of minority organizations which are engaged in economic activity. Such organizations may include individually-owned businesses, consumer cooperatives, and various forms of nonprofit community corporations. The nature of managerial assistance provided may extend from review and criticism of proposals through participation in management seminars through on-site consulting to actual physical participation in the operation of the business. The duration of the interaction also may vary considerably from with-

\footnotetext{
See, e.g., T. Cross, Black Caprtalism (1969); E. Foley, The Achieving Ghetto (1968). For a more comprehensive analysis and proposal, see McLaurin \& Tyson, The Gheddiplan for Economic Development, in Black Economic Devezopment $\mathrm{r} 26$ (W. Haddad and G. Pugh eds. rg6g). For a more complex treatment of the barriers to minority economic development, see L. Durham, Black Capitalisas (1970).
} 
drawal by the majority participants once the business or organization is initially established to continued participation over several years.

Initial differentiation of the many possible forms of managerial assistance may be achieved by distinguishing between efforts on the part of individuals and programs which exist under the auspices of some controlling organization. Many majority businessmen, government officials, students, and others have on an individual basis contributed generously of their time and effort to assisting minority businessmen and community organizations. The greater amount of managerial assistance, however, is provided through organized programs rather than by individual practitioners. Since this is likely to continue to be true in the future, the remainder of this paper will focus on organized programs. Much of what is to follow in terms of critique and prescription for organized programs could, of course, also be profitably applied to individual efforts.

In describing various programs of managerial assistance, there are two primary dimensions which must be considered. First, there is the nature of the assistance to be provided, and here there are two polar types. The first involves the importation of management, as where a corporation provides a managerial work force on either a loan or permanent basis to operate a plant or other facility in a minority area. The duties of this managerial work force usually include both the efficient operation of the facility in normal business terms and the identification and training of minority group members who would then gradually take over the management positions. $^{3}$ The second polar type involves the provision of consulting services to new or existing minority businesses. In these cases, operating responsibility is vested in the minority manager who has available for consultation experts in the various functions of business drawn from participating corporations and other organizations. There are also a variety of intermediate positions along this dimension including various types of seminar and classroom training programs for minority businessmen conducted either by university faculties or participating businessmen.

Consultation itself may be provided under many guises. Among the more familiar of these are (a) the nonprofit agency, such as the Interracial Council for Business Opportunity (ICBO) which serves as a clearing house, bringing together volunteer business executives and minority entrepreneurs; (b) assistance provided as a condition of financing, either under the auspices of venture capital corporations or through commercial banks; and (c) university programs, which use graduate business students and faculty as consultants, often on a fee basis. It is not within the scope of this paper to attempt to review and discriminate among the myriad of programs now existing or being planned across the country; a comprehensive com-

\footnotetext{
${ }^{8}$ If normal business standards are not used in estimating the viability of minority enterprises, then the survival of such enterprises will be dependent on continued subsidies from the sponsoring organizations. This runs directly counter to the symbolic and growth potential goals of minority economic development.
} 
pendium of managerial assistance programs has been developed by the Department of Commerce. 4

In addition to the distinction between importing a management team and providing consulting aid to indigenous managers, the second major dimension is the choice between programs aimed at providing assistance to existing minority enterprise and those concerned with establishing and assisting new enterprise. To some degree these two dimensions are correlated, for the possibility of importing management teams is probably greater in new enterprises than it would be in the fortifying of existing enterprises. This is particularly true when we consider that much of the currently existing minority-owned business in the country falls into the category of small retail or service-type businesses. It is possible, however, to conceive of assistance programs which provide management teams for existing businesses which are at a critical growth stage or which provide consulting services to new businesses.

It is probably inappropriate to attempt to argue that one or another of the possible combinations of types of assistance and types of business is the most preferable or the most desirable in a program of community economic development. These several combinations represent different aspects or starting points in the same process. Thus, if the goal of managerial assistance programs is to foster the fuller involvement of minorities and minority areas in the economic system, then each of the possible combinations of importation, consultation, and new and established businesses may be desirable, but their desirability may be determined by differing circumstances.

\section{Importing a Management Team}

Several desirable characteristics can be identified in a program which relies on the importation of a management team and the establishment of a new enterprise. First, the importation of a management team generally occurs when an existing corporation has decided to "adopt" a minority enterprise and has made a commitment to its future. The new enterprise may be engaged in producing a product which is needed by the parent corporation, or the parent corporation may in some manner be acting to guarantee the market of the minority enterprise, at least during its formative years. ${ }^{5}$ To the extent that the parent corporation's prestige and self-image are committed to the success of this project, the prospects for the minority enterprise may be quite bright.

\footnotetext{
'U.S. Department of Commerce (Office of Minority Business Enterprise), Private Progrums Assisting Minority Business (I970). See also B. Flower, Business Amid Urban Crisis (Studics in Public Affairs \#3) (1968); National Industmal Conference Bonrd, The Role of Business in Pudlic Afrarrs (Studies in Public Affairs \#2) (I968); Cohn, Is Business Meeting the Challenge of Urban Affairs?, 48 Harv. Bus. Rev. 68 (I970).

${ }^{5}$ It is essential that there be a real growing market for the products of the minority enterprise. New ventures into marginal product areas, even if subsidized, are not likely to succeed. See L. Durram, sthpra note 2.
} 
A second desirable characteristic of the adoption process is that it connects employees and managers drawn from the minority community into the larger organization. This creates a spin-off of jobs for minority residents and brighter prospects of career development for the emerging group of minority managers. Thus, importation programs offer guaranteed short run success, are generally larger in scope than individually started business enterprises, and can provide more jobs for the minority area. These jobs can incorporate training and development programs and provide links to larger career paths for minority employees and managers.

These are, of course, ideal conditions, and there are many pitfalls in the path of such programs. First, the willingness of corporations to engage in such programs is clearly tied to the leverage that they have available to them as a result of economic conditions. It is unlikely, at the time that this is being written in late I970, that the market place for such new business ventures would be as favorable as it was only a few years ago.

A second problem in the realization of the full potential of such programs is the possibility of distrust in the minority community itself. It is not always true that the potential for job training and upgrading of management has reached fruition. Much of the criticism of job placement and manpower training programs for minorities has been leveled at the lack of upgrading and career possibilities. A final problem is that the end efforts of the imported management team may be to amplify the dependency of the minority employees and managers-in-training on this team. If the successful adopted minority enterprise is seen as being successful only because of the efforts of the majority participants, then the enterprise will make only a minimal or perhaps a negative contribution to the development of the minority business sector. Since one of the major concerns in developing a minority business sector is to provide success models and leadership for the minority area, successes in minority enterprises which are attributable mainly to majority participants are of little value. Thus, importation programs for developing new enterprises are likely to contribute to minority economic development only under favorable economic conditions which will stimulate the participation of large corporations, only when these corporations follow through on the promise of training and upgrading, and only when there is a true transfer of responsibility, authority, and control to the minority management.

\section{Consulting with Existing Businesses}

A second combination is the program which provides consulting services to existing businesses. Attention will be focused on management consulting activities which are directly relevant to the ongoing operations of the business. These would include direct advice on such things as inventory planning and control, bookkeeping and accounting systems, promotional displays, and customer-employee relations. Off-job aspects of managerial assistance programs which are concerned with broader 
issues of the minority businessman's managerial development, such as seminars, extension programs, and other educational efforts, will be considered below.

In contrast to the "importation-new business" combination described above, programs emphasizing direct consultation on the ongoing problems of existing businesses are less grandiose in prospect, but probably more in tune with conditions and possibilities in minority areas. First, the target population for such programs already exists. Such businesses are generally beset with many problems including survival, financial and physical, and an overworked owner-operator. Further, the scale of operations of such businesses normally facilitates the assessment of these problems and the establishment of priorities for their resolution. Since programs of consulting to established minority businesses generally function by means of direct contact between one consultant or a team of business experts with the minority entrepreneur, it is generally possible to move directly to programs and proposals for improving the performance of the business. The small scope of operations-in terms of total volume, number of employees, and structural complexity-and the consequent availability of immediate feedback on the effects of actions, make it possible for the consultant to become immediately involved in the operating process of the business. The impact of the consultant is tangible and has immediate consequences.

It may also be true, of course, that the impact of successfully consulting with an individual businessman on the economy of the minority area may be less than the long-run impact of a successful new venture established under a parent corporation's protection. ${ }^{6}$ A successful program of consultation to established businesses, however, has several desirable characteristics which tend to counteract this possible disadvantage. First, the impact of successful consulting efforts with local businessmen is likely to be immediate and readily observable to the community at large. Secondly, such programs are relatively insensitive to short-run fluctuations in economic conditions in the larger system since sizeable long-run commitments of capital and manpower are not necessary in order to get such programs functioning. The fact that the small businesses involved are already operating provides a further insulation from fluctuating economic conditions since the emphasis of the program is on performance of an operating enterprise and not on locating surplus capital and manpower which could be invested in a new project. ${ }^{7} \mathrm{~A}$ third characteristic is that the program is "wired in parallel," that is, the failure of one of the small businesses involved in a program of consulting in a minority area does not directly affect the

\footnotetext{
${ }^{\circ}$ Again, the emphasis on small business does not imply that it is an end in itself, but a vehicle for fostering more extensive and significant economic development.

To the extent that the problems of a particular small business revolve around acquiring capital either to support current operations or to expand, general cconomic conditions will clearly mediate the business' access to the capital markets, whether or not the business has available expert consultation from a managerial assistance program. The point is that consultation with small businesses represents a continuing process and does not, therefore, depend on the making of recurring judgments which aro sensitive to economic conditions.
} 
probabilites of success of the other businesses involved. Thus, consulting programs can accumulate successes while not being seriously debilitated by failures; programs which rely on the importation of new business generally only have one shot at success or failure. Finally, the symbolic impact of a series of success stories of small businessmen who maintained operating control and responsibility throughout the managerial assistance phase of their business history is probably greater and more responsive to the self-image needs of the minority community than would be the impact of a new business which was controlled and operating primarily by majority participants during its critical development stages.

There are, however, several serious pitfalls in the "consulting-existing business" route. These include the volatile nature of small business and the difficulties in developing and maintaining adequate systems for monitoring the interactions of individual consultants with their businessmen-clients. The client-consultant relationship is critical to the success of such a program, and yet it is highly susceptible to many kinds of breakdowns. The lifespan of most small businesses is rather short and the failure rate of new ventures is quite high. There is no reason to expect that the experience of small business in minority areas would be any more favorable. Thus, serious and diligent effort by a competent consultant is no guarantee of the eventual success of the business. The possibility that consultants may be less than ideally serious and diligent underscores the need for an efficient monitoring system.

\section{B. Critical Elements in Choosing an Approach}

It should be clear from the two combinations developed above that the remaining possibilities-consulting to new business ventures and importing management to operate existing businesses-are really special cases in the general process implied in the two examples given. Summarizing these examples, it becomes clear that the critical elements in evaluating or examining managerial assistance programs or in making the preliminary decision of what type of program is most appropriate at a given time and a given area include the following:

(a) the existence of opportunities to initiate a managerial assistance program; these might include the presence of an indigenous small business sector or the matching of favorable economic conditions and corporate needs with the possibilities of establishing a new venture;

(b) the probabilities that the enterprises receiving assistance will be successful;

(c) the nature of the interaction between minority and majority participants;

(d) the symbolic impact of the program on the minority community;

(e) the contribution that the program makes to improving the participation of the minority community in the larger economic system.

The following discussion focuses on assistance programs which involve consulting to existing businesses. This approach was chosen for detailed consideration because it speaks most directly to the immediate, short-run needs of the minority community, 
is best insulated from fluctuations in general economic conditions, and provides immediate, active contact with the existing minority economic system. ${ }^{8}$

Part II of this article will develop the notion of a "consulting to existing business" program further by examining the various levels of approach which fall into this classification. Part III will develop criteria which might be used in selecting and formulating a specific program and will examine some of the decisions which must be made in the preliminary planning stages. The application of this model to the establishment of a specific program will then be described in part IV. Part V will examine in somewhat greater detail the operating experiences of this particular program and will attempt to develop general guidelines for avoiding serious pitfalls in fulfilling the promise of managerial assistance to minority economic development.

\section{II}

\section{An Overview of Consulting Programs}

\section{A. The Sources of Support}

\section{The Federal Government}

The notion of programs of consulting to small business covers a wide range of specific formulations, which vary widely among themselves. While an exhaustive listing is probably not possible, a brief description of some of the more common types might be useful. The federal government, as well as many state and local governments, provides a wide range of managerial assistance to small businesses. These include an entire catalogue of brochures, pamphlets, and other "how to" materials designed to aid the businessman in establishing, incorporating, putting into operation, and managing his business. Other governmental services include the maintenance of agencies and local offices which can provide a wide variety of assistance to businessmen who come in with their problems. The best known of these programs is the Small Business Administration (SBA). ${ }^{9}$ Assistance may involve the provision of loan funds, the insuring of loans obtained from commercial sources, or several types of operating assistance. In most cases, programs which involve the government as a participant in a loan arrangement have required the participating businessman either to accept consulting assistance from the government agency itself or to acquire it through some other source. In recent years, such special programs as MESBIC and Model Cities, which are discussed in detail by other authors in this symposium, have had required managerial assistance as an integral part of their formulation. ${ }^{10}$

\footnotetext{
${ }^{8}$ For another discussion of these issues which reaches a somewhat different conclusion, see L. DunHAM, supra note 2.

${ }^{-}$An extensive listing of government programs is given in Department of Commerce Handoox FOR SMALI Business (I969).

${ }^{10}$ This new emphasis on managerial assistance may stem in part from a recognition that much, if not all, of the problems of a small businessman are problems of operating management and not of financing per se. The recognition that the infusion of funds is, at best, usually a stop-gap measure which
} 


\section{The Business Community}

The participation of the business community has also taken many forms. Most commonly, corporations have permitted, or in many cases encouraged their employees to devote some of their time to working with minority businessmen. ${ }^{11}$ For those employees who choose to serve as consultants, the relationship or the contact with the businessman is generally not made through employers but through some other organization or agency. In many cases, individual consultants make their own contacts but the use of an organizational mediator is more common. These mediators include nonprofit community organizations established primarily for the purpose of providing managerial assistance, such as Interracial Council for Business Opportunity (ICBO), government agencies such as the SBA (which utilizes retired executives in its SCORE program and active managers in its ACE program), ${ }^{12}$ local economic development agencies, and, in some cases, university operated programs. In most cases, business consultants normally serve as volunteers on their own time although there are instances where the company permits the individual to set aside a certain amount of his working time for managerial assistance activity. ${ }^{13}$

Another source of managerial assistance has been the recent institution of organizations intended to provide financial and operational assistance to minority entrepreneurs. In New York City, for example, the Urban Coalition has founded the Coalition Venture Corporation whose task it is to provide, or serve as an intermediary in the securing of, capital funds for new and established businesses. Coalition Venture also provides a consulting service for its clients. There are several other organizations similar to Coalition Venture which seek to couple financial assistance with ongoing management consulting. Other examples from the New York area include the Bedford-Stuyvesant Capital Corporation and Capital Formation, Inc. ${ }^{14}$

\section{New Consulting Firms}

On the profit-making side, there have emerged in recent years a small but growing number of consulting firms, largely black-owned and operated, whose principal business activity is the provision of consulting to minority entrepreneurs.

does not speak to the real needs of minority entrepreneurs is substantiated by the experience reported in part $\mathrm{V}$ of this paper.

11 For illustrative examples, see Cohn, supra note 4; B. FLower, supra note 4 .

${ }^{12}$ SCORE (Service Core of Retired Executives) and ACE (Active Corps of Executives) are described in HaNDBOoK FOR SMALI Business, stpra note 9, at I76.

${ }^{13}$ In some instances, notably in the banking industry, the nature of the corporation's activities bring it into direct contact with minority entrepreneurs and, in these cases, the employee may be serving as a consultant directly under the auspices of his corporation.

14 See Private Programs, Assisting Minority Enterprise, supra note 4, at 178 , I81. In all, forty-two private programs of managerial assistance are listed for New York City. In comparison, eighteen programs are listed for Washington and twelve for Chicago. Questions of redundancy and possible benefits of coordination have not been seriously examined to date. 
While these firms occasionally have individual businessmen as clients, the more common arrangement is with a businessmen's association or community development organization, often with the financial support of a government loan or grant program. While the future of these firms is yet to be decided because of their relative youth, their existence is an encouraging sign if we interpret it as an indication of the growing strength and vitality of minority enterprise.

\section{The Universities}

Finally, there are a number of existing consulting programs under the auspices of universities, particularly urban universities. These programs are generally located in the graduate business school and use graduate students (MBA's) as consultants with back-up support and guidance from the faculty. As these programs have grown, alumni, particularly those who were consultants during their student days, have also begun to participate in the programs. Such programs have no loan funds of their own and are normally involved in consulting on operations, although assistance to the businessman-client in the preparation of loan applications is also a major activity. The author has worked closely with a program of this type over the past three years; the experience of this program will be used (in part IV) as a vehicle for exemplifying the principles of a good managerial assistance program to be described in part III. The following sections consider a general managerial assistance program and describe the critical characteristics of such a program. It is recognized, however, that of necessity there will be many variations in the theory and in the practice of managerial assistance programs depending upon the area, the identity of the sponsors, and the particular needs and characteristics of the local business community.

\section{B. Supplementary Development and Training Efforts}

The above description of the classes of managerial assistance programs has focused primarily on the direct provision of consulting services to a businessman-client in his place of business. That is, the primary concern was with assistance aimed at improving day-to-day operation of the small business and at solving the immediate, pressing problems of such businesses. In addition to this primary focus at keeping the small businessman in business and making the enterprise profitable in the short run, most of the programs described above subscribe to the parallel goal of developing the small businessman's general abilities as a manager. This means that the consultant is not only concerned with solving the immediate problem of the small businessman, but also with improving the businessman's ability as a problem solver. This may entail helping the businessman come to a clear perception of his role as manager; it may also involve encouraging him to participate in job training programs. Most programs recognize that their efforts to solve pressing problems of their small business clients are stop-gap measures and that it is not enough to keep these businesses alive; they must also become self-sustaining. For this reason, most 
programs of consulting to small businesses incorporate some notion of off-job training generally in the form of attendance at conferences or seminars designed to increase the businessman's technical competence and general managerial ability. As with the types of consulting assistance, there are many off-job educational programs currently in operation. These range from intensive seminars or conferences of one or two or three days duration which focus on a particular issue such as advertising, franchising, or factoring of accounts receivable, through ongoing workshops which meet regularly over several weeks, to rather full-scale educational programs which attempt to provide a complex introduction to managerial training.

For example, AUCOA, in New York City, regularly conducts a course in the preparation of bids and other specific competitive problems of small contractors. ${ }^{15}$ On a more elaborate level, ICBO runs throughout New York City and several other parts of the country the Business Opportunities Workshop program which provides an intensive fifteen session course in the several major facets of small business operation. These are only a few examples of the possible programs in continuing education which might be conceived as concomitants to consulting on operations. The remainder of this paper will concentrate on the criteria and issues involved in the establishment and operation of programs of direct consulting on current operations. The necessity of accompanying such programs with efforts to enhance the specific technical competences and ability of the minority entrepreneur, perhaps through formal training programs, should be evident from this discussion.

\section{III}

\section{Detrerminants of a Successful Program: A General Model}

\section{A. Basic Criteria}

We turn now to a consideration of the characteristics that should be incorporated in an efficient program of providing managerial assistance to minority enterprises. Focusing on programs which provide consulting assistance to existing businessmen, it is evident that at least four overriding criteria must be met if the program is to succeed.

(a) Acceptance. Planning and conception, the manner of introduction, the identity of the sponsoring organization, its consultants and the target population, and the operating procedures of the consulting organization are critical factors in determining whether or not the consulting effort will be accepted by the minority community. Note that if the program is to have maximum impact, it must be accepted not only by the minority business clients, but also by the rest of the minority community.

(b) Empathy. This is an intangible quality, but the consulting organization and its field representatives, the consultants, should have a sensitive prior understanding

${ }^{15}$ AUCOA (Association of United Contractors of America) is a non-profit organization of minority contractors in New York City. 
of the conditions and circumstances of small business, should be flexible in recognizing and responding to the needs of their clients, and should be capable of finding grounds for effective exchange of information.

(c) Knowledge. Small business is a specific example of business in general; it is also a unique activity. Application of general business knowledge to the specifics of small business requires a careful and conscious translation process which is often overlooked by the providers of managerial assistance. To the extent that there are unique characteristics in the operation of a minority enterprise, an equally sensitive and conscious additional translation must be made.

(d) Reliability. Organizations and individuals who enter into consulting arrangements with minority businessmen must be completely reliable in fulfilling these commitments. Emergencies in the home office for the volunteer businessman, exams for the student, and special meetings for the government official may all be perfectly valid reasons from their viewpoints for missing a meeting with the minority clients. From the minority perspective, however, this can and frequently is viewed as one more piece of evidence that the majority participants are not sincere in their efforts. Another aspect of reliability is that the consultant frequently will be leading his client out on to what is shaky ground for the client. Programs initiated by the consultant often exceed the current competence of the client. Without adequate follow-up by the consultant such programs may do more harm than good. ${ }^{16}$

It is probably true that a variety of well run and well conceived programs could satisfy these four conditions, regardless of whether the program was under the auspices of government, business, community, or university sponsors. The underlying premise of managerial assistance programs-that they contribute to the long-run growth and development of the minority business community-suggests some further considerations which might guide the choice among possible sponsoring organizations.

Economic development programs can do harm as well as good, particularly if they are not in tune with the needs and perceptions of the community being served or if the lifespan of the program does not coincide with the period needed for individual businesses to reach maturity. This consideration suggests that desirable programs should be instituted under the sponsorship of organizations which are in close and continuing contact with the community, that the sponsoring organization must recognize that its commitment must be relatively permanent, and that the program must be reasonably well insulated from exogenous decisions. As has been suggested, empathy, acceptance, and reliability are at least as important as knowledge in motivating a successful program. Further, the stipulation of freedom from exogenous decisions suggests that the long-run success of the program depends on its freedom

\footnotetext{
${ }^{10} \mathrm{~A}$ related aspect of reliability is the problem of consultant turnover. In terms of impact on the minority businessman, there is a considerable difference between a continuing association with a managerial assistance program and a continuing association with a specific consultant. Frequent changes in the consulting team can greatly deter progress.
} 
from concern over random fluctuations in the larger economy as well as relative freedom from the need to search continually for operating funds from external agencies. ${ }^{17}$ This analysis would suggest that programs initiated by communitybased organizations or by other organizations who have their permanent roots in the minority community would be preferable, particularly if they are on a "pay-asyou-go" or endowment basis.

\section{B. Specific Operating Characteristics: The Model}

The problem is to define requirements which will make the program acceptable to the community, capable of providing the specific technical business services that it promises, and capable of eliciting the continuing commitment of the sponsoring organization. A program which satisfies these requirements would have to have the following characteristics:

(a) The program must be seen by all parties involved as serving their own selfinterests.

(b) The program must be responsive to individual and communal self-image needs.

(c) The program must overcome normal barriers to communication.

(d) The program should avoid the consultation-community participation morass.

(e) The program should take care to keep expectations from outpacing results.

(f) The program should provide and extend the legitimacy for parties involved.18

\section{Shared Self-Interest}

Perception of shared self-interest is a necessary precondition to establishing any program which will exist over time. Institutions will become involved in black economic development only to the extent that they are convinced that it serves their own self-interest. Programs initiated on a self-interest basis are, of course, capable of servicing social goals. It is not necessary to assume that the self-interest of the various sectors are mutually exclusive. The intricate relationships between the minority economy and the larger economic system have been outlined. It should be obvious that the health of the minority economy necessarily contributes to the health of the total economy. On the local level, moreover, many institutions and organizations find themselves in a position where their future markets, manpower

\footnotetext{
${ }^{17}$ For example, many managerial assistance programs are started with seed money provided by a foundation, the federal government, or some other institution. These funds enable the assisting organization to begin operation and to create expectations in the minority community. Frequently, however, funds run out just as the organization is beginning to function effectively, and the organization must then divert its efforts away from its businessmen-clients to the task of fund raising. When such an event occurs, it does harm to the direct consulting relationship and also to the trust and confidence vested in the program by the community and the clients.

${ }^{18}$ An expanded development of this model and of the history of MBA Management Consultants, Inc. is given in Ference \& Fraser, White Involvement in Black Economic Development, I5 J. Soc. \& BeHuv. Scr. (1969). See also Casten, MBA Management Consultants: Blueprint for Student Involvement, MBA 3, I969; Sloane, Management Aid for Harlem Business, N.Y. Times, May 3, I969 (Business and Finance), at 1 , col. 4 .
} 
sources, and political environments are concentrated in a growing minority community. ${ }^{19}$ Perceptions of shared self-interest provide insurance of participation by the sponsoring organization. Further, the perception by the minority community that the consulting program is providing a benefit to the sponsoring organization is a more readily understandable and acceptable motive for the sponsoring organization than is a vague sense of social responsibility. Shared self-interest also provides some guarantee that the decisions and actions of the assistance program and the specific advice and suggestions of consultants will be guided by realistic, hard-nosed business criteria and not by wishful thinking. Thus, the perception by all parties that they have "a piece of the action" insures that the regular rules of the game are being used. ${ }^{20}$ All too often, majority consultants forget the rules and procedures that they use to make decisions in their own business when advising their minority clients. This frequently leads to unsound decisions, which in turn weaken the survival chances of the minority business. Self-interest and strict adherence to the rules of the business game are socially responsible as well as economically defensible.

\section{Self-Image Needs}

Responsiveness to individual and communal self-image needs implies that programs cannot be developed and initiated by the sponsoring institution acting on its own. Moreover, programs cannot be promoted as helping the minority businessman to better himself if they do for him things that he cannot do for himself. Such a paternalistic posture usually hampers any useful coming together of the sponsoring organization with the local business group or the larger community. Such an approach effectively prevents the minority businessman from developing his own potential as a manager and from expanding his market beyond his immediate community. An acceptable managerial assistance program, therefore, will take the form of a rational partnership wherein all parties contribute and derive from the activity. By recognizing shared self-interest, with tangible quid pro quo for all parties, all parties can retain the freedom to initiate or reject proposals and to terminate the relationship. This assures that responsibility for program adoption and for subsequent success is shared fully by the minority entrepreneur. Programs which are consistent with this premise contribute to the symbolic and practical development of self-sufficient minority enterprise.

\section{Effective Communications}

Circumventing communication barriers is essential if managerial assistance programs are to move beyond stylized interactions which currently typify majority-

\footnotetext{
${ }^{20}$ This has been particularly true of many of the major power companies and of large urban universities, which might explain why these institutions have been among the first to become active in community development programs.

${ }^{20}$ The "piece of the action" for many sponsors of management assistance programs is by way of an investment in the entire minority area rather than a commitment to a specific business. For some organizations, however, the piece of the action is just that-an equity share-a minority business.
} 
minority relationships. Emphasis is usually placed on points of difference as the participants act out ingrained social roles such as that of the militant, philanthropist, superior, or subordinate. In all of these roles, there is no assumption of a commonality of interests. The minority businessman is a petitioner humbly or aggressively seeking the benefits from the majority controller of resources. Attempts to communicate within these roles are not likely to produce any revisions of thinking nor effective movement toward improved operations of minority enterprises. It is necessary, therefore, to focus on similarities in the relationship such as common interests and practical experiences in business, expertise in particular functions or aspects of business, and adherence to the value of business as a way of life. The majority consultant brings to the relationship his knowledge of sound principles of general management while the minority entrepreneur brings practical experience and expertise in the technology of a particular enterprise; both bring a particular view of reality based on their experiences. The consultant is likely to have as difficult a time in adapting his knowledge to the peculiar conditions of business in the minority community as the minority entrepreneur will have in absorbing the advice and reasoning of the consultant. In order for programs of managerial assistance to get off the ground and to succeed over time, the sponsoring organization and its representatives must continually demonstrate their respect for and dependence on the special knowledge and skills of the minority entrepreneurs with whom they work.

\section{Community Involvement}

In terms of transforming a program of managerial assistance from an idea to reality, many well-intentioned programs have foundered on the issue of community participation in the planning and initiating of the program. Consulting the community on matters that effect it is an intuitively appealing principle on both moral and political grounds. Those organizations which have attempted to achieve a community consensus before initiating their programs, however, have often found the process to be counterproductive. Adherence to a criterion of shared self-interest would seem to preclude engaging in the tedious and politically dangerous process of consultation. It is impossible to reach an accord with every community group, particularly since the groups in any given community are likely to have sharp disagreements among themselves. A program of consulting to existing businesses seeks to avoid the potential dangers of community participation by establishing direct relationships between individual entrepreneurs and the consulting organization. One specific implication of this position is that programs initiated at the behest of minority businessmen are more likely to be successful because the consulting organization has been invited into the area.

\section{Controlling Expectations}

A major pitfall facing all community oriented programs is the possibility that the expectations generated by the announcement of the program will continually outpace 
the results produced by the program. This is particularly true, of course, if the announcement of the program occurs months or years before the program is actually put into operation. Well-intentioned programs can founder for many reasons, including conflicts of interests, unreasonable projections of impact, and the simple passage of time between inception and results. When this occurs, expectations are thwarted and the underlying mistrust of majority intentions is reinforced in the minority community. Two specific implications follow from this point. First, programs which can be inaugurated with a minimum of publicity are preferable. Second, publicity should follow upon actions and should reflect accomplishments of the program. Programs of consulting to minority businessmen can fulfill both of these ambitions, particularly if publicity concerning the program is held to a minimum until after the program is well into operation and evidences of success in specific consulting-client relationships are available. ${ }^{21}$

\section{Preparing for the Future}

Consulting to minority business is a necessary first step in drawing the minority economy into proportionate participation in the larger economic system. It follows that programs of managerial assistance ought to provide extended legitimacy for the parties involved. The participants in the program must be consciously aware of the need to link their efforts to a larger process of change and development. $\mathrm{Ob}$ servance of the preceding conditions imply that programs of consulting to small business will initially have a fairly limited potential effect. In order to have significant impact on the economic conditions of minority areas, programs will have to affect larger numbers of people, providing concrete results and leverage for future programs. The logical next step will evolve out of experience with programs aimed at individual businessmen, but only if the participants in those programs consciously attend to the need to look for the next steps.

\section{IV}

\section{MBA Management Consultants, Inc.: The Model Applied}

\section{A. Developing the Program}

The Columbia Graduate School of Business, for a variety of reasons, sought in 1968 to become involved in the economic development of Harlem. Columbia University is physically situated in Harlem, a factor which provides sufficient reason for concern about the economic development of the area. Other factors, such as the interests of students and faculty, overtures from the business community, and a desire to demonstrate the school's capabilities, were also operative. It was recog-

\footnotetext{
${ }^{21}$ It would be charitable to say that institutions which seek much advanced publicity are naive with regard to the relation between expectations and performance. It is probably more often a case that such institutions are as much concerned with their public image and their troubled consciences as with the people that the programs are supposed to help. By avoiding publicity, sponsoring organizations should be able to disassociate themselves from this past history and programs of questionable motivation.
} 
nized that a massive influx of people from the School of Business into Harlem or the masterminding of major development programs would feed upon the feelings of suspicion and antagonism which Harlem had developed toward Columbia. It was decided that the school would not initiate programs on its own but would constitute itself as a skills broker in the managerial assistance field, providing the services of faculty and students to whatever groups or individuals sought them. Skills brokerage is on the surface a passive concept. In practice, existing word of mouth communication networks were utilized as a means of encouraging requests for assistance from the community. Thus, the school provided speakers for many occasions, acted as organizational design consultants for some community action groups, conducted a blue ribbon seminar in minority business development, and met with a broad spectrum of business-oriented groups. These exchanges provided many leads, but only those which offered a reasonably high probability of success were pursued beyond the information exchange stage. This decision was based on a recognition of the school's limited resources and on the perception that association with ineffective projects would hinder acceptance as a participant in other efforts.

The school decided to focus upon providing consulting to existing minority entrepreneurs. This choice was prompted by several factors. First, the small business sector seemed most likely to provide a steady flow of relationships; there are three to four thousand minority-owned businesses in Harlem, most of them small. These independent entrepreneurs provided a viable point of entry into the community. Second, the business students had been looking for opportunities to make some contribution to community development. It seemed that exposure to small, operating concerns would be a reasonable vehicle for tapping their skills without getting them in beyond their capabilities. Third, relations with individual businessmen would be roughly independent of those with other clients. None of these affiliations would be large enough initially to attract a great deal of attention. This would provide the program with a chance to succeed or fail on its own merits. Finally, the school had received specific overtures from a reasonably successful entrepreneur who was seeking whatever managerial assistance might be available. This initiation provided an ideal entry for establishing the program.

Out of these considerations emerged what is now MBA Management Consultants, Inc. ${ }^{22}$ Two or three member teams of graduate business students serve as consultants to individual businessmen. The student team also has access to a faculty advisor. MBA began as a student activity but has recently become a nonprofit membership corporation. Membership in the corporation is held by the minority entrepreneurs who are the clients and the students who are their consultants. The corporation is governed by a fifteen-man board of directors, elected by the membership. Seven members of the board are businessmen, four are drawn from the Graduate School of Business, and the remaining four are representatives of the New York

\footnotetext{
${ }^{22}$ See Ference \& Fraser, supra note I8; Sloane, supra note r8.
} 
business community. Daily operations are managed by a full-time director and a staff of five student officers who work part time. Student consultants are compensated for their services from funds donated for that purpose. The original funding of the program was provided mainly by the Urban Center of Columbia University and Arthur D. Little, Inc. Future plans for financing the corporation include the transferral of part of the financial burden to the clients, perhaps on a fee basis, and an enlarged fund raising program. After two and one-half years of existence, MBA is now actively engaged in consulting with forty separate businesses and utilizing the services of approximately ninety students and about twenty-five faculty and advisors. ${ }^{23}$ In some cases, alumni of the school who had participated as consultants during their educational program have continued to work with their clients on a voluntary basis.

\section{B. The Consulting Relationship: The Model Implemented}

The student-businessman relationship is structured in terms of the typical managerial consulting relationship. It is a typical business arrangement. The businessman contracts for the consulting service. $\mathrm{He}$ is not obligated to accept the consultants' suggestions and he retains the right to reject a particular consultant or team at any time. Thus, the student-consultants are in the "employ" of the businessman. The businessman-client gains access to the specialized knowledge of the students but retains the discretion of applying this knowledge to his own operations. The student-consultants earn a reasonable wage (three dollars per hour) and derive the benefits of the client's years of practical experience. The consultants' experience in the job market at graduation has shown that this exposure to the real world is a readily marketable commodity. Thus, at the individual level, the consulting relationship represents a clear case of shared self-interest and avoids threatening the selfimage of either party. It is particularly clear that the student gains as much from the interaction as does the businessman. ${ }^{24}$

The management consulting relationship also speaks directly to the need to circumvent communication barriers. The consultant-client relationship does not challenge the intelligence or ability of either party; it asserts that they have different types of competence. The client is a practicing businessman, immersed daily in all the problems of running a business. His knowledge, while often intuitive and unsystematic, is comprehensive. His concern with keeping afloat from day-to-day has most likely prevented him from doing much planning or from examining the deficiencies of his activities. The student-consultant is receiving specalized training in a variety of formal techniques and approaches. He can serve as a technical

\footnotetext{
${ }^{23}$ In its three-year history, over two hundred students have participated as consultants to over sixty businesses.

${ }^{2 t}$ From the school's perspective, there is also a sharing of self-interests. The school is likely to remain in close physical proximity to Harlem and, thus, involvement in the economic development of the area represents an investment in long-run survival and stability. The consulting experience is also a valuable addition to the student's education, and one which would be impossible to simulate in the classroom.
} 
specialist in the solution of specific problems. He also fills a broader role, that of an objective outside observer. He thus can provide both the incentive and the justification for the client to take a careful look at his enterprise. Exchanges between consultant and client allow both parties to examine their activities and try out new ideas. A consultant provides the lever necessary for the client to develop his skills as a manager and planner. The client in turn provides a sounding board for examining the practicality of the ideas and theories of the consultant. Each is, therefore, both student and teacher. This common ground can act to break down communication barriers while protecting the integrity of the individuals involved.

Of the remaining considerations, the needs to avoid publicity and the political difficulties of community consultation are fulfilled by basing the program on affiliations with individual businessmen. The final premise-that of legitimizing future programs-should follow from satisfaction of the above premises. It can be seen that a program conceived along the lines of MBA Management Consultants, Inc., satisfies the basic requirements of a successful managerial assistance program that were outlined in part III. The continued existence and growth of MBA demonstrates that these requirements are valid. This is not to say that MBA has experienced no difficulties. In fact, the problems that it has experienced relate directly to the primary criteria of acceptance, empathy, reliability, and knowledge identified above.

\section{Operating Problems: Failures to Satisfy the Model}

The problem of general acceptance has been the most readily resolvable. The student's motives are seen as a mixture of the desires to perform some socially beneficial work and to gain some useful experience (and also, in some cases, to earn a modest income). These motives are acceptable to the minority businessmen and go a long way toward easing fears of exploitation.

On the level of the individual enterprise, however, the most serious practical difficulties in the program have been in developing adequate rapport between specific clients and consultants and in satisfying the participants in the program that the program is really benefiting the clients. There is no question but that the studentconsultants have reaped great benefits and that the image of the business school in the community has been enhanced. But the assessment of the impact on the community and on the individual clients is much more difficult to ascertain. The problem of rapport is treated in part $\mathrm{V}$; the problem of assessment of impact deserves further consideration here.

Frequently, programs of managerial assistance assume that their very existence will provide a "good" to the community and to the individual businessmen who participate. There are many possible piffalls in such programs. First, there is the issue of whether the managerial assistance program is speaking to the true needs of the minority entrepreneurs. An emphasis on short-run capital financing when the true survival concerns revolve around managerial behavior is likely to do more 
harm than good and dissuade both the community and the sponsoring organizations. Second, most programs of this type utilize expressions of greater knowledge, better communication, or feelings of improvement as measures of success of the program. While these subjective criteria are undeniably important, an assessment of normal business parameters must be made before judging the worth of the program. ${ }^{25} \mathrm{Un}$ fortunately, minority businessmen are often unwilling to make the necessary data available for examination and record keeping purposes. Without some measure of profit, gross revenue, sales volume, or other pertinent indicator of economic performance, it becomes extremely difficult to assess the impact of any given program. Finally, managerial assistance programs face the need of obtaining the resources necessary to continue in operation. Frequently, such programs are funded for a specific time either by the government or by some other sponsoring organization. When the funding period expires, or the money runs out, the program must seek renewal or search for new funds. It becomes extremely difficult to justify requests for new funds without performance measures. Yet, the benefits derived for both majority participants and the munority community from a successful managerial assistance program can be lost rather rapidly if the program goes out of business before its job is completed. Thus, lack of adequate performance measures greatly exacerbates the second major problem of MBA Management Consultants, Inc., and most other managerial assistance programs-the continued availability of operating funds.

MBA has been funded for specified time periods by two major grants and by smaller contributions from several corporations. It is apparent that the continued operation of MBA will hinge upon the willingness of corporations and other funding agencies to provide working capital. As was suggested earlier, this dependence on exogenous decision makers is not the most desirable situation. It would be preferable if MBA could receive a sufficient endowment to guarantee its long-run existence or if it could establish itself on a "pay-as-you-go" basis. Under present circumstances, neither of these conditions seems likely to be realized. Thus, in the future, as it has in the past, MBA will be engaging in an effort to secure funds from corporate and government sponsors.

A final problem experienced by MBA has been that in many cases the needs of the businessmen often go beyond the specific competencies of the student-consultants. The students can provide assistance at a reasonably sophisticated level across the general range of business problems. However, for the businessman who has particularly thorny problems in bookkeeping, inventory control, or some other issue, the need for an expert in that area is often great. MBA is currently attempting to elaborate on its present consulting technique by establishing teams of experts, composed of either student or alumni specialists, who will serve as consultants on specific problems within the area of their expertise.

\footnotetext{
${ }^{25}$ An approach to assessing the viability of minority enterprises as targets for managerial assistance and development is given by L. Durias, supra note 2.
} 
D. A Look to the Future: Redesign and Expansion

These four problems-rapport, assessment of impact, funding, elaboration of technical competence-indicate instances where MBA has yet to fully realize the requirements of the general model outlined in this paper. At the present time, the organization is attempting to evolve to a slightly modified form which will be better suited to resolving these difficulties. In general, this form will include teams of experts in particular areas who will join with the general management consultant. It will also include the establishment of a fee for clients in order to place at least part of the funding of the organization on an independent basis. It will utilize a more formal set of performance measures so that MBA can get a better insight into its impact.

One further development in the growth of MBA which is worthy of note is that the organization is beginning now to move beyond its concern for the operation of individual businesses toward acting as a body on issues of concern to all businesses in the community. For example, MBA is currently planning an effort to improve the access of minority businessmen to burglary and fire insurance. Other programs in developmental stages include participation of the organization in community planning activities, the establishment of a summer job program for high school students, and the utilization of experienced clients as consultants to other minority businesses. It is this last set of programs, indicative of the continuing growth and strength of MBA, which go farthest toward justifying this approach as a means of fostering economic development in minority areas.

\section{$\mathrm{V}$}

\section{MBA Management Consultants: The Field Experience}

\section{A. The Small Businessman}

The consulting relationship basically begins with the problem of establishing rapport between client and consultant. The consultant, by virtue of his training, is oriented toward formal accounting systems, delegation of authority, long-range planning, and quick, decisive action. The client, for a variety of reasons, is likely to be intimately involved in every aspect of his business. The client is an expertalthough a self-taught one-in his particular field, be it shoemaking, boiler maintenance, or building rehabilitation. He may be uncomfortable with delegating authority to subordinates and accustomed to performing all the functions of the business himself. He is likely to want to oversee every sale, purchase, and inventory decision personally, and to be reluctant to think of himself as a manager with executive responsibilities. He may be lax in separating his personal and business finances and may resist efforts to formalize his bookkeeping practices. He is likely to be too busy to indulge himself in long-range planning and is probably more comfortable with daily receipts as opposed to forecasts. This thumbnail sketch is typical of MBA 
businessmen-clients and points out some of the major obstacles to realizing an effective consulting arrangement. Examination of these characteristics of the small business will identify the areas in which assistance is most frequently needed as well as the types of behavior required of the consultant if he is to be successful.

The small businessman, minority or otherwise, is a uniquely American species, having opted to go it on his own. While it is dangerous to generalize about so diverse a group, MBA's clients share many of the following six attributes:

(a) Ambivalence toward authority. Most clients were led to set up their own businesses by a desire to avoid taking orders from someone else. At the same time, they resist delegating responsibilities to their employees. The client typically supervises all of his employees directly and requires that all decisions be cleared by him. The impetus for establishing a small business often comes from earlier failures in the larger economic marketplace. The client gains considerable gratification from the association with the entrepreneurial tradition and usually feels that his continued presence is essential to the survival of the business. The consultants, who view the development of a managerial definition of one's role as the critical stage in transforming a small business into a corporate entity, have found their most difficult task to be assisting the client to adopt a managerial perspective.

(b) Boundless personal energy. Clients often express the fear that the managerial role would be dull, overly limited, and "out of touch." These individuals thrive on personal contact, on immersing themselves in the rush of daily activity, and on the challenge of keeping their heads above water in the face of conflicting pressures and demands. This drive and tenacity is a major source of strength for the businessman. It is, however, a potential source of difficulty in developing the organization and individual employees.

(c) Susceptibility to the gambler's malaise. Most clients believe firmly in the golden opportunity-the big score. They are frequently engaged in several marginally related enterprises. Each time a new deal presents itself, they cannot resist taking a flyer because "this one may be the big one." This dilution of the manager's effort and of his working capital often gets in the way of taking actions which would insure the growth and stability of the organization.

(d) A static short-run view of time. Most small businessmen do not engage in much planning, mainly because of the pressures on their time coming from the daily flow of events. Appointments may not be kept; deliveries, bills, and taxes may be late or overlooked. Work is frequently not scheduled, but rather is done as pressure from customers requires. This static viewpoint often interferes with the attempts of consultants to establish control systems.

(e) An undifferentiated view of one's business and personal life. The small businessman often runs his treasury out of one pocket and his personal finances out of the other, with frequent transfers in both directions. He may not pay himself a regular salary but will draw cash for his personal needs from the cash register. 
Clients frequently see their most pressing need as one of obtaining working capital. The consultants cannot normally begin to work on this issue until they have been able to separate the client's business from his personal life.

(f) Adherence to a conspiracy theory. The client frequently views the main barrier to his personal success as a lack of capital and discriminatory treatment by the banking and credit systems. These problems are intimately related and contain considerable truth. Historically, minority businessmen have experienced considerable difficulty in obtaining loan funds, in getting accounts receivable factored, and in obtaining and paying for insurance and other services. This precludes a comfortable cash flow and creates problems in maintaining inventories and providing credit. This situation often leads the businessman to see the solution of these financial problems as providing the entire key to his success. This focus on financial issues very often interferes with the resolution of the very real managerial problems described above.

These six characteristics provide some indication of the variety of issues and problems which have emerged in the client-consultant relationship. It is evident, first of all, that the consultant must realize that the client does not necessarily share his view of what is rational. A main problem in consulting to minority businessmen is to find some mutually agreed upon set of operating procedures and systems which are necessary to the continued functioning of the business. Systems seen as crucial by the consultant frequently have little immediate appeal to the client. The consultant must not only concern himself with translating the work of his proposals to the client, he must also look to the development of the client's personal competence.

\section{B. Pitfalls for Consultants}

A particularly seductive and dangerous pitfall in managerial assistance programs is the fostering of a dependency relationship between client and consultant. The consultant must be continually aware that his role is just that, a consultant, and not a functioning member of the business. His legitimate functions are to investigate and analyze, advise and advocate. Thus, the consultant may develop and propose programs and then act as an advocate, but it must be the client who decides whether a proposal is to be adopted. To the extent that the client becomes dependent upon the consultant for direction, decisions, and approval, the underlying goals of managerial assistance programs have been thwarted. If the consultant is setting policy and making operating decisions, the goal of fostering an independent, viable minority business community is not being realized. In addition, the potential for developing the client's managerial abilities and self-confidence will have been lost. Also, the potential symbolic contribution of flourishing minority business will be jeopardized and possibly even lost if the community perceives that these businesses are being sustained primarily through the efforts of outside parties. The danger of allowing dependency relationships to emerge is considerable, since the consultant 
often first encounters the businessman at a time when the the businessman is undergoing a crisis, and the consultant is easily seen as the only means of survival available. Dependency is also fostered by the initial differences in sophistication and technical competence between client and consultant. ${ }^{26}$ The consultant must be aware of the potential for dependence and must carefully guide his own actions so as to maximize the client's acquisition of competence and self-confidence. It is relatively easy for the consultant to fall into the trap of "doing it himself," rather than taking the extra time which might be necessary to explain a new idea fully to the client and to allow the client the time to reflect upon and practice it.

In addition to avoiding the formation of a dependency relationship, the consultant must also be constantly aware of the difference in accountability between himself and the client. What to the consultant may be a laboratory for the testing out of new ideas is to the client his livelihood, his identity, and perhaps his only chance for success. The consultant, in his advocate's role, has the obligation to evaluate risks from the client's perspective. The consultant must remember that he is not engaged in an intellectual exercise wherein he may test pet theories or experiment with alternative procedures; the client is engaged in a business activity where profit and loss, success and failure, have immediate impact.' This means that the consultant must adapt his proposals to the realities of the client's situation. Very frequently what is sound in terms of management theory or has been effective in large corporations is not directly applicable to the running of a small business in a minority community. The consultant must learn to be sensitive to the client's assertion of what will not or cannot work for him. He must recognize that the client's unwillingness to embark upon grandiose expansion efforts or visionary programs may represent a realistic appraisal of possibilities in his market as well as an aversion to risk.

A final pitfall to be avoided on the consultant's side is the frequently voiced assumption that all of the problems of minority business can be explained away by an infusion of sufficient funds. The client himself may frequently express such an opinion, but the consultant through careful observation often comes to realize that this financial insolvency is a symptom of broader deficiencies in managerial capacity. Thus, while much of the effort of MBA consultants has been directed to financial matters, particularly in the establishment of bookkeeping and other control systems, they have also dealt extensively with questions of executive responsibility and delegation, planning, and the development of information systems. In many cases, the consultant never quite gets around to dealing with the specific problems that led the client to seek assistance from MBA. For example, in assisting a client to put

\footnotetext{
${ }^{28}$ In psychological terms, the consulting relationship is a supportive one, much like therapy. As in therapy, the critical task is to transform the relationship to one where the support provided by the consultant is minimal and limited to specific areas of differential expertise. This transformation can be impeded either by the client's unwillingness to accept increased independence or by the consultant's unwillingness to encourage it.
} 
his business in order so as to be able to apply for financial aid, a consultant will often be led to deal with and resolve a number of operational and managerial problems, the resolution of which may greatly decrease the need for additional funds. It is imperative that both consultant and client look beyond the quick adoption of simplistic panacea for the ills of small business-such as short-term capital inputsand look toward establishing the systems, plans, and managerial practices needed for long-run stability and success. The avoidance of these pitfalls-dependence, use of the small business as a laboratory, identification of cure-all solutions-depends primarily upon the consultant. This implies that consultants should have a realistic view of the role of small business, a willingness to view themselves as technicians or experts in specific areas of competence, and an openness to learning from association with small businessmen. The success of any program of managerial assistance hinges critically on the competence, adaptability, and sensitivity of the consultants who will work with the small businessmen. ${ }^{27}$

\section{VI}

\section{Some Concluding Remarks}

This paper has presented a broad description and analysis of the role of managerial assistance programs in minority economic development. The analysis focused first on a delineation of the several ways that managerial assistance might be packaged and then on a discussion of the broad criteria and operational considerations which are critical to the success of such programs. The path to success for minority economic development efforts has many crucial elements-motivation of the participants, selection of ventures, design and implementation of the program, perceptions and behaviors of the parties involved-and there are many piffalls which threaten even the most well-intentioned programs.

It has been shown that the interrelation of economic systems may provide the motivation for serious efforts to generate fuller involvement of minority areas in the national economy. Thus, majority participants can appeal to self-interest in supporting managerial assistance programs. The thrust of the argument, moreover, is that only those programs which are undertaken with a recognition of self-interest are likely to be successful. A sense of social responsibility, admirable as it may be, is a rather ephemeral star on which to pin the hopes of a community.

The selection of economic development ventures is particularly crucial. Minority enterprises must be judged on their potential for independence, growth, and performance; that is, the regular "rules of the game" must be used. Enterprises which

\footnotetext{
${ }^{27}$ This also underscores the importance of the consultant's commitment. A successful effort with a minority businessman hinges on building a trust relationship between client and consultant. This cannot be done if consultants are unreliable or have unrealistic expectations about the nature of small business in minority communities. These factors lead to high turnover of consultants and can destroy the program. See Ference \& Fraser, supra note 18.
} 
require a continuing subsidy to survive or which deal in products which have limited or declining markets should be avoided.

There are many choices to be made in the design and implementation of the program: sponsor-government, business, community agency, university; targetnew or existing businesses; type of assistance-importing a management team, consulting to minority businessmen, seminars and training programs. While it is recognized that any of the possible combinations of these factors may produce a successful program, this article has focused on the "consulting to existing businesses" approach, using a university-based program as a specific example. In addition to economic viability, successful design and implementation were seen to depend upon satisfaction of four criteria: acceptance, empathy, knowledge, and reliability. These criteria were then used to develop an operating model; the components of the model reflected efforts to avoid the major pitfalls in the institution of managerial assistance programs. Briefly, these pitfalls include the recognition of shared selfinterest as motivator and guarantor of continued participation, responsiveness to selfimage needs and communication barriers, avoidance of the political dangers of community participation and of the temptation to exaggerate expectations through excess publicity, and incorporation of individual programs in a larger perspective of continuing development.

The eventual success of programs flowing from this or similar models ultimately rests on the perceptions and behaviors of the participants. In describing the organization and operating experience of MBA Management Consultants, Inc., the characteristics of clients and consultants and the nature of the consulting relationship have been stressed. Small businessmen-minority businessmen-are individuals, but individuals who share many characteristics and perceptions. The consultant must be sensitive to these; he must also be sensitive to the temptations of fostering dependence, to the different stake that the client has in the success of his business, and to the deceptiveness of "cure-alls" such as capital infusion.

To summarize, managerial assistance is essential to effective minority economic development, but its provision cannot follow any simple, automatic formula. Minority business is still business and, in the end, the rules of the game will take their toll of poorly conceived, designed, or monitored programs. Minority enterprise must be economically viable if it is to survive, and managerial assistance programs must be acceptable, emphatic, knowledgeable, and reliable if they are to fulfill their promise. Anything less than full observance of the sense and importance of these criteria by majority or minority participants will not suffice. 